\title{
Agricultura Apoiada pela Comunidade: poderia a experiência dos agricultores americanos ser útil para os agricultores urbanos brasileiros?
}

\author{
Marina Castelo Branco ${ }^{1}$; Ronaldo S de Liz²; Flávia A Alcântara ${ }^{3}$; Hélio AG Martins ${ }^{4}$; James C Hanson ${ }^{5}$ \\ ${ }^{1}$ Embrapa Sede-DPD, SAIN Parque Rural, Av. W3 Norte (final), 70770-901 Brasília-DF; 2Embrapa Hortaliças, C. Postal 218, 70359-970 \\ Brasília-DF; ${ }^{3}$ Embrapa Arroz e Feijão, C. Postal 179, 75375-000 Sto. Antonio de Goiás-GO; ${ }^{4}$ UnB, Campus Darci Ribeiro, Asa Norte \\ 79919-970 Brasília-DF; ${ }^{5}$ Extension Economist, Agricultural \& Resource Economics (AREC) 2200 Symons Hall, Univ. of Maryland Col- \\ lege Park, MD 20742 USA; castelo@embrapa.br; alcantara@cnpaf.embrapa.br; setti@cnph.embrapa.br; helio@unb.com.br; jhanson@ \\ arec.umd.edu
}

\section{RESUMO}

O projeto "Agricultura Apoiada pela Comunidade" (AAC) é uma alternativa de mercado utilizada na Europa e nos EUA. Neste mercado alternativo, os produtores oferecem a sua produção aos consumidores, sob a forma de cestas de alimentos, alguns meses antes de iniciarem a produção de suas culturas. Algum tempo depois, durante alguns meses, os consumidores irão receber os produtos. Atualmente, diversos países têm uma parcela significativa da sua população vivendo na pobreza. Por isso, diversas políticas públicas foram desenhadas nesses países com o objetivo de reduzi-la. $\mathrm{O}$ estímulo à agricultura urbana é uma dessas políticas. No entanto, frequentemente, os produtores urbanos pobres têm dificuldades para adquirir os insumos necessários para manter a sua produção. $\mathrm{O}$ apoio contínuo do governo local associado ao apoio contínuo da comunidade local poderia ajudar esses produtores a manter o seu sistema de produção. E, para esses agricultores urbanos pobres, o projeto AAC poderia ser um meio alternativo de organização. $O$ objetivo desse trabalho foi obter algumas informações sobre o projeto AAC nos EUA e avaliar se consumidores e produtores urbanos pobres de uma cidade brasileira de baixa renda aceitariam se engajar neste tipo de projeto. Os produtores americanos envolvidos no projeto AAC em geral cultivavam uma área inferior a $2 \mathrm{ha}$, ofereciam diferentes tipos de hortaliças aos consumidores por pelo menos quarto meses e geralmente usavam práticas de produção orgânica. No entanto, havia dificuldades para a manutenção do projeto, sendo o planejamento da produção e a dificuldade de sua manutenção ao longo do tempo os maiores problemas. Alguns consumidores da cidade brasileira pesquisada se mostraram dispostos a participar deste tipo de projeto principalmente pela possibilidade de receberem alimentos frescos e produzidos organicamente. No entanto, o mesmo não ocorreu com os produtores urbanos pobres da cidade. E a razão principal para isso foi a impossibilidade deles garantirem a produção. Pesquisas posteriores deverão avaliar se a melhoria do sistema de produção poderia levar esses agricultores a se engajarem neste tipo de projeto.

Palavras-chave: agricultura urbana, redução da pobreza, organização alternativa.

\begin{abstract}
Community Supported Agriculture: could the experience of American farmers be useful to Brazilian urban farmers?

Community Supported Agriculture (CSA) is an alternative food market used in Europe and in the USA. In this alternative market, farmers offer their production to consumers in the form of shares some months before they begin to produce their crops. Sometime later, during some months, consumers will receive the goods. Nowadays, several countries have a significant portion of their population that lives in poverty. Several public policies have been designed to reduce poverty in these countries and the stimulus to urban agriculture is one of these policies. However, poor urban farmers frequently have difficulties to purchase the inputs to continue with their food production. The continuous support of the local government associated to the continuous support of the local community could help those farmers to maintain their urban production. And for those poor urban farmers a CSA could be an alternative way of organization. The objective of this work was to get some information of CSAs from USA and find whether consumers and urban farmers from a poor Brazilian town would like to be engaged in this type of project. American CSAs generally occupied an area smaller than 2 ha, offered consumers different types of vegetables for at least four months and most of them used practices of organic production. However, there were several difficulties to run this project and the most important ones were planning and maintaining the production system. Some consumers from a town in Brazil were willing to engage in a CSA project mainly because they would receive fresh and organic products. Yet, poor urban farmers from this town did not show willingness to engage in a CSA project. Their main reason was that they were not able to control their production system. Further research could try to find if an improvement in the production system could lead farmers to engage in this type of project.
\end{abstract}

Keywords: urban agriculture, poverty reduction, alternative organization.

(Recebido para publicação em 3 de agosto de 2010; aceito em 14 de dezembro de 2010) (Received on August 3, 2010; accepted on December 14, 2010)

\begin{abstract}
$\mathrm{A}_{\mathrm{p}}^{\mathrm{p}}$ partir do final do século passado, políticas públicas que contribuíssem para reduzir a pobreza e aumentar o consumo familiar de alimentos tanto em termos de qualidade, quanto em quantidade, passaram a ter maior ênfase. O Programa de Agricultura Urbana e Pe-
\end{abstract}

riurbana desenvolvido pelo Ministério do Desenvolvimento Social e Combate a Fome faz parte dessa política. O financiamento desses projetos, por meio de parcerias com prefeituras, oferece apoio técnico e social a agricultores urbanos e periurbanos de baixa renda. Os projetos financiados devem, entre outros aspectos, "promover a agroecologia, o consumo com hábitos saudáveis, o respeito à diversidade étnica, racial e cultural, a equidade de gênero e a participação, empoderamento e autonomia do/as agricultores urbanos e periurbanos" (Ministério 
do Desenvolvimento Social e Combate a Fome, 2009). Outras instituições governamentais federais, estaduais e municipais, além de ONGs, também financiam esse tipo de projeto.

No entanto, os recursos disponíveis para a manutenção dos projetos no longo prazo é muitas vezes incerto; mudanças de governo podem eliminar os recursos disponíveis para a agricultura urbana (Villas Bôas, 2006). Em outros casos, os projetos são financiados por um curto período de execução, normalmente dois a três anos. Em qualquer um desses casos, o resultado é que os agricultores urbanos não conseguem manter-se na atividade devido à limitação de capital. Com isso, os projetos não atingem um dos objetivos da política delineada pelo Ministério do Desenvolvimento Social e Combate a Fome: a autonomia. A regulamentação da agricultura urbana poderia impedir que mudanças de governo afetassem o andamento dos projetos. $\mathrm{O}$ crédito bancário cooperativo poderia ser uma alternativa para a obtenção de capital quando os projetos acabam. Por exemplo, o Banco Palmas, no Ceará, concedia financiamento a agricultores urbanos sem a necessidade de pré-requisitos como consulta a cadastros, verificação de renda ou garantias (Segundo, 2002). Essa organização alternativa de acesso ao crédito poderia ser viabilizada em alguns locais, mas não em outros, devido às dificuldades inerentes à sua organização (necessidade de pessoal especializado entre outros). Assim sendo, para a busca da autonomia dos produtores urbanos e periurbanos, outras formas de organização social, que envolvessem agricultores, governos, ONG's e a comunidade local, ou seja, os consumidores, poderia ser uma alternativa. A experiência de outros países poderia contribuir para essa organização.

Uma alternativa poderia ser o mercado alternativo de incentivo à produção local de alimentos, adotado nos Estados Unidos e Europa e denominado "Agricultura Apoiada pela Comunidade (AAC)". Na década de 1970 esse mercado foi introduzido, a partir da experiência européia, nos Estados Unidos. Ele é basicamente um acordo entre agricultores e consumidores, onde os agricultores oferecem a sua produção aos consumidores, sob a forma de cestas de hortaliças, alguns meses antes que os produtos comecem a ser cultivados. Posteriormente, em um mês pré-acordado, e por um período de tempo definido, os consumidores recebem os seus produtos. Isso permite que os agricultores obtenham o capital necessário à manutenção de sua produção, sem necessidade de acesso a algum tipo de crédito bancário (Cooley \& Lass, 1998). Em 2007, o Censo Agrícola norte-americano verificou que 12.549 agricultores estavam envolvidos nesse mercado alternativo (National Agricultural Statistics Service, 2009).

Assim sendo, o objetivo desse trabalho foi descrever a organização do mercado alternativo AAC nos Estados Unidos, sob o ponto de vista dos agricultores, e verificar a sua aceitação por agricultores e consumidores urbanos da cidade de Santo Antônio do Descoberto, uma cidade de baixa renda do estado de Goiás. Para responder a essas perguntas, primeiro foi conduzida uma pesquisa com agricultores americanos que participavam do mercado em diversos estados americanos. Após isso foi avaliada a disposição de consumidores e agricultores urbanos em participar de um projeto desse tipo em Santo Antônio do Descoberto.

Mas qual a razão da escolha da cidade de Santo Antônio do Descoberto para essa avaliação? Essa cidade, localizada a 48 km de Brasília, é caracterizada como cidade dormitório. Os trabalhadores dessa cidade são geralmente trabalhadores com baixa qualificação e de baixa renda (Castelo Branco et al., 2006).

Em 2004, com a conjuntura favorável à implantação de políticas públicas de redução da pobreza, o governo municipal disponibilizou um terreno abandonado para a implantação de uma horta urbana. No período 2004-2007, com o apoio da Embrapa Hortaliças e do CNPq, 25 famílias cultivaram, em lotes individuais de $300 \mathrm{~m}^{2}$, mais de 20 tipos de hortaliças. Uma parte da produção era usada para consumo o que levou a melhoria da dieta das famílias. $\mathrm{O}$ excedente de produção era comercializado diretamente aos residentes da cidade ou em supermercados locais, o que gerou aumento na renda das famílias de apro- ximadamente $20 \%$. A renda obtida com a comercialização das hortaliças era quase toda usada para o atendimento das necessidades básicas das famílias (Castelo Branco, 2007; Oliveira \& Santos, 2007). Em 2008, já sem o auxílio dos parceiros externos à cidade, e com apoio errático do governo local, o projeto era ainda uma atividade informal. Nessa época contava com 13 famílias. No início de 2009, apenas oito famílias participavam do projeto. A redução no número de famílias ocorreu por vários motivos: alguns agricultores se mudaram da cidade, outros encontraram um melhor trabalho formal ou informal, outros não tinham capital para cultivar seus lotes e outros simplesmente desistiram de participar. Os agricultores que continuavam na horta tinham dificuldades para adquirir os insumos necessários à produção. É problema comum nos países em desenvolvimento agricultores pobres tentando cultivar suas terras com pouco suporte financeiro e governamental (Pessôa, 2006; Villas-Bôas, 2006). Assim, projetos que busquem viabilizar a autonomia financeira desses produtores podem ser uma estratégia para a redução da pobreza no longo prazo. O mercado alternativo "Agricultura Apoiada pela Comunidade" poderia ser então uma das estratégias a ser utilizada para a viabilização desses projetos.

\section{MATERIAL E MÉTODOS}

Entendendo o projeto "Agricultura Apoiada pela Comunidade (AAC)"

- Inicialmente foram selecionados 23 estados americanos para esse trabalho, usando como critério os aspectos de relevância econômica e região do país. Foram selecionados os estados de Alabama, Arizona, Califórnia, Colorado, Delaware, Flórida, Georgia, Iowa, Kentucky, Louisiana, Maryland, Michigan, Mississipi, Montana, Nebraska, Novo Mexico, New York, Carolina do Sul, Oklahoma, Pensilvânia, Texas, Utah e Virginia.

No endereço www.localharvest.org/ csa estavam registrados 1.200 agricultores que participavam desse mercado alternativo. Usando essa base de dados foram enviados 570 questionários para todos os agricultores dos estados 
selecionados, via Internet, entre $9 / 10$ e 11/12/08. Perguntas sobre a área total da fazenda e a área desta destinada à produção de hortaliças, número de cestas de hortaliças oferecidas, formas de distribuição das cestas e sistema de produção eram as perguntas principais. Informações sobre o número de anos de participação no mercado, período de produção e número de hortaliças oferecidas nas diferentes estações do ano foram retiradas diretamente da página de cada organização. Para a análise de dados foi utilizada a estatística descritiva.

Disposição dos consumidores de Santo Antônio do Descoberto de participar do mercado alternativo "AAC" - Uma pesquisa, usando um questionário semi-estruturado, foi feita na cidade em 03/09. Informações relacionadas a tamanho da família, renda familiar mensal, tipos de hortaliças consumidas e desejo de participar nesse tipo de projeto foram as perguntas principais. Para a determinação do desejo dos consumidores de participar nesse projeto, foi explicado inicialmente que diferentes hortaliças orgânicas seriam produzidas na horta urbana local e eles teriam que adquirir uma cesta com hortaliças diversas, com uma antecedência de dois meses. Após essa pergunta, os consumidores foram inquiridos se aceitariam participar do mercado, ainda que isso envolvesse o risco de receber cestas diferentes a cada semana.

Uma amostra de 31 potenciais consumidores foi escolhida ao acaso em uma rua localizada a $3,5 \mathrm{~km}$ da horta urbana. Aárea escolhida era considerada bem desenvolvida e contava com toda a infraestrutura básica. Isso significa que nessa área deveriam estar famílias que consumiam hortaliças regularmente. Outras áreas da cidade não eram tão desenvolvidas e o consumo de hortaliças era bastante limitado (Castelo Branco et al., 2006). Para a análise dos dados foi utilizada a estatística descritiva.

Disposição dos agricultores urbanos de Santo Antônio do Descoberto de participar do mercado alternativo "AAC" - uma pesquisa, usando um questionário semi-estruturado, foi realizada na horta comunitária em 04/09. Apenas seis dos oito agricultores foram encontrados. Foram coletadas infor- mações sobre o sistema de produção, tipos de hortaliças cultivadas, destino da produção e disposição de participar no mercado alternativo. A explicação do projeto fornecida a esses produtores foi a mesma explicação inicial fornecida aos consumidores e descrita no item anterior. Para a análise dos dados foi utilizada a estatística descritiva.

\section{RESULTADOS E DISCUSSÃO}

Entendendo o projeto "Agricultura Apoiada pela Comunidade (AAC)" - Do total de 570 questionários enviados, 108 (19\%) foram respondidos; 57\% dos questionários foram recebidos um dia após o envio dos mesmos. Isso sugere que nesse tipo de pesquisa uma alta proporção dos questionários deve ser respondida imediatamente. Isso poderia ocorrer pela disponibilidade de tempo do respondente ou pelo interesse em responder as perguntas.

Com referência ao tempo de participação no mercado alternativo, 53\% dos agricultores participavam há menos de quatro anos e $15 \%$ há mais de 10 anos, o que denota que a maioria dos participantes era relativamente nova. Em relação à área total das propriedades, $79 \%$ das fazendas tinham menos de 20 ha. $74 \%$ das áreas destinadas à produção de hortaliças para o mercado alternativo ocupava uma área de menos de 2 ha (Figura 1). Resultados semelhantes foram obtidos por Oberholtzer (2004) e Tegtmeier \& Duffy (2005) quando avaliaram o mercado alternativo AAC em algumas regiões americanas.

As cestas continham seis a 15 tipos de hortaliças diferentes e eram distribuídas aos consumidores em períodos variados do ano. Fazendas localizadas no sul, devido às condições climáticas favoráveis, atendiam os consumidores durante todo o ano. Já as fazendas localizadas no norte, pelas mesmas razões climáticas, atendiam os consumidores por um período de quatro a seis meses.

O número de cestas comercializadas foi variável. Aproximadamente $80 \%$ dos agricultores comercializavam menos de 50 cestas/ano. Diferenças no número de cestas comercializadas foram observadas entre produtores com a mesma área de cultivo (Figura 2). Essas diferenças podem ter ocorrido por várias razões. A primeira poderia ser o número de hortaliças comercializadas em cada cesta, o que significa que, quanto mais produtos em uma cesta, menor a área de cultivo para cada produto. Uma segunda razão poderia ser a diferença entre sistemas de produção, o que resultaria em diferentes produtividades (Cooley \& Lass, 1998).

Os agricultores adotaram diferentes maneiras para distribuir as suas cestas: na fazenda, em pontos de distribuição nas cidades ou entrega em domicílio. Distribuição na fazenda $(32,3 \%$ dos agricultores) ou combinação de distri-

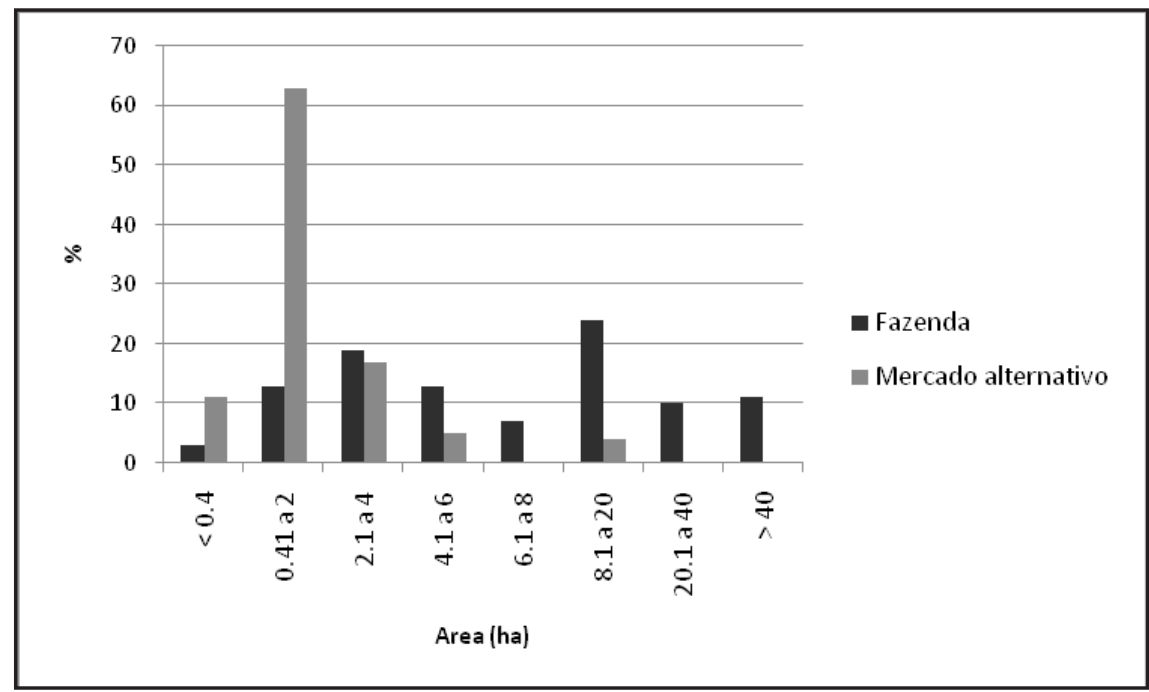

Figura 1. Área da fazenda e área do mercado alternativo "agricultura apoiada pela comunidade. ( $\mathrm{n}=92$ ) (farm area and community suppported area). College Park, Universidade de Maryland, 2008. 


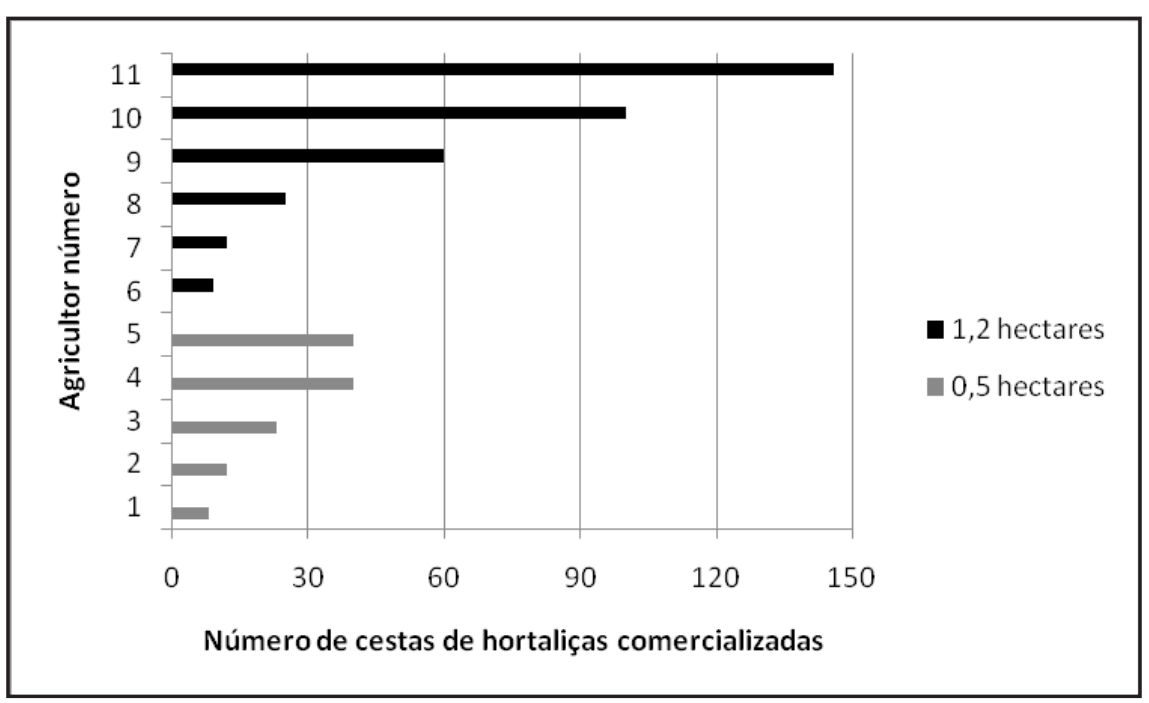

Figura 2. Número de cestas de hortaliças comercializadas pelos agricultores que participavam do mercado alternativo AAC (number of shares sold by CSAs). College Park, Universidade de Maryland, 2008.

buição na fazenda e nas cidades $(28,4 \%$ dos agricultores) foram as formas mais comuns. A entrega em domicílio foi realizada por apenas $7,8 \%$ dos produtores.

O número de cestas distribuídas pelo produtor e a distância da cidade certamente foram fatores que influenciaram no tipo de distribuição adotada. Um produtor comentou que "minha fazenda está a $90 \mathrm{~km}$ da cidade e eu tenho muitos consumidores. Você já imaginou todas essas pessoas vindo aqui? Os problemas ambientais poderiam aumentar, devido ao aumento do consumo de combustíveis". Esse aumento no consumo de combustíveis certamente aumentaria as emissões de $\mathrm{CO}_{2}$ e teria como consequência um maior custo ambiental. Para um exemplo, imaginemos as seguintes situações:

Situação 1: 100 pessoas viajam 1600 $\mathrm{km} / \mathrm{semana}(16 \mathrm{~km} /$ pessoa $)$ para pegar a cesta durante 22 semanas. Essas pessoas usam um veículo que faz $10,5 \mathrm{~km} / \mathrm{L}$ de gasolina, o que significa que $8 \mathrm{~kg}$ de $\mathrm{CO}_{2}$ são emitidas para cada litro de gasolina consumido (http://www.epa.gov/ otaq/climate/420f05001.htm). O custo ambiental da emissão de 1 ton de $\mathrm{CO}_{2}$ foi estimado em US\$5,00 (Sohngen \& Sedjo, 2006), sendo que US $\$ 1,00$ valia em 28/06/10, de acordo com o Banco Central, R\$1,78.

Situação 2: as mesmas 100 cestas são distribuídas na cidade e as mesmas
100 pessoas vão buscá-las caminhando. $\mathrm{O}$ agricultor viaja $16 \mathrm{~km} / \mathrm{semana}$ e utiliza uma van que consome um litro de gasolina a cada $7 \mathrm{~km}$.

Situação 3: a situação é semelhante a situação 2 , no que se refere ao deslocamento do produtor, mas os consumidores viajam $3 \mathrm{~km}$ usando o mesmo tipo de veículo da situação 1 para pegarem as suas cestas.

A Tabela 1 fornece os resultados da análise das três situações, e a hipótese do produtor é confirmada. O custo ambiental de distribuição das cestas na fazenda foi 66 vezes maior do que o custo ambiental de distribuição na cidade, onde os consumidores pegavam as suas cestas caminhando. Pirog \& Rasmussen (2008) encontraram resultados semelhantes no que se refere à emissão de $\mathrm{CO}_{2}$ ocasionada pelos diferentes tipos de distribuição de cestas.

A produção orgânica foi a produção predominante, sendo que a produção não certificada era predominante (Figura 3 ). Diversas razões foram apontadas pelos produtores para não certificarem seus produtos: alto custo da certificação e um grande número de documentos que demandavam um tempo excessivo para serem preenchidos foram as principais. Isso porque os documentos deveriam conter informações sobre "a história de uso da terra, planos de rotação de culturas, manejo de solo e pragas, fontes de sementes, insumos usados para cada cultura, sistema de plantio, produção, tecnologia de colheita e registro de vendas e selos de certificação" (Baier, 2005). Como o mercado alternativo AAC permitia uma relação direta entre produtores e consumidores, a certificação não era considerada importante pelas partes.

A participação no mercado alternativo apresentava várias vantagens. Alguns produtores consideraram como vantagens apenas os benefícios privados. Segundo um produtor "é o único meio de obter o capital para produção". Outros produtores consideraram benefícios sociais, econômicos e ambientais. Um produtor comentou que "era a maneira de se fazer dinheiro enquanto se produzia boa comida para as pessoas que conhecia, com reduzido impacto ambiental". Outro comentou que "o modelo do projeto combinava com a sua personalidade e permitia que ele se conectasse com a comunidade e colaborasse em sua construção. Além do mais ele tinha a oportunidade de educar as pessoas sobre a importância da agricultura local para o desenvolvimento da comunidade".

No entanto, ainda que o mercado alternativo apresentasse vantagens, algumas dificuldades também eram encontradas. Entre elas podemos citar a pressão para produzir grande variedade de hortaliças por um longo período de tempo, a necessidade de planejar bem a produção para evitar a falta ou o excesso de produtos e a necessidade de satisfazer o desejo dos consumidores em alguns itens. Mas a dificuldade principal era, sem dúvida nenhuma, o planejamento da produção, uma vez que os agricultores não podiam prever a ocorrência de pragas, doenças ou inundações com antecedência.

Em resumo o mercado alternativo AAC apresenta dificuldades e vantagens. Ele pode garantir o capital inicial para produção, aumentar a produção de alimentos locais de boa qualidade com menor impacto ambiental, melhorar a relação no interior da comunidade e incrementar a economia local. Por outro lado, há uma dificuldade no planejamento da produção. Para os agricultores urbanos pobres do Brasil, a possibilidade de obtenção de um capital adiantado e 
Tabela 1. Simulação de parte dos custos ambientais associados a três maneiras distintas usadas pelos consumidores para pegar suas cestas de hortaliças (simulation of part of environmental costs of three different ways used by consumers to pick up their shares). Brasília, Embrapa Sede, 2010.

\begin{tabular}{clcccc}
\hline Situação & \multicolumn{1}{c}{ Descrição } & $\begin{array}{c}\text { Distância } \\
\text { viajada }(\mathbf{k m})\end{array}$ & $\begin{array}{c}\text { Gasolina } \\
\text { utilizada (L) }\end{array}$ & $\begin{array}{c}\text { Emissões de } \\
\mathbf{C O}_{\mathbf{2}} \text { (t) }\end{array}$ & $\begin{array}{c}\text { Custo ambiental } \\
\text { estimado }\end{array}$ \\
\hline 1 & $\begin{array}{l}\text { Cestas distribuídas na fazenda. } \\
\text { Cestas distribuídas em um local urbano e }\end{array}$ & 35.200 & 3.352 & 26,81 & 47,73 \\
2 & $\begin{array}{l}\text { recolhidas por consumidores que se deslo- } \\
\text { cavam a pé. }\end{array}$ & 352 & 50,28 & 0,40 & 0,72 \\
3 & $\begin{array}{l}\text { Cestas distribuídas em um local urbano e } \\
\text { recolhidas por consumidores que se deslo- } \\
\text { cavam de automóvel. }\end{array}$ & 6952 & 678,85 & 5,43 & 9,67 \\
\hline
\end{tabular}

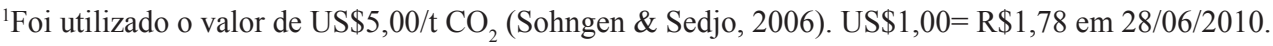

o apoio da comunidade poderiam ser fatores que colaborassem para a manutenção da agricultura urbana no longo prazo. Para os consumidores, a possibilidade de obter alimento fresco também poderia ser uma vantagem. Tendo em vista esses diferentes benefícios, foi avaliada a possibilidade de produtores e consumidores de Santo Antônio do Descoberto participarem desse mercado alternativo.

Disposição dos consumidores de Santo Antônio do Descoberto de participar do mercado alternativo "AAC" - Das 31 pessoas entrevistadas em Santo Antônio do Descoberto, 70\% pertenciam a famílias com quatro a cinco pessoas e $90 \%$ delas era composta por trabalhadores que recebiam no máximo dois salários mínimos. Todos os entrevistados adquiriam hortaliças para consumo regularmente. Alface, tomate e cheiro verde eram os produtos mais consumidos, conforme observado anteriormente (Castelo Branco et al., 2006). Apenas três consumidores entrevistados adquiriam produtos da horta urbana local, os quais eram levados às suas casas pelos agricultores. Por outro lado, os outros 28 entrevistados iam ao Mercado Central para realizarem as suas compras. Para todos esses consumidores o mercado alternativo seria então uma vantagem?

Dezenove consumidores (61\%) responderam que aceitariam participar do mercado alternativo. A possibilidade de receber hortaliças frescas e a conveniência do acordo foram apontadas como as principais vantagens. Ou seja, foram apresentadas razões de cunho privado. Ajudar os produtores ou a comunidade, razões sociais, foram citadas por apenas dois consumidores. Este resultado foi semelhante ao obtido por O'Hara \& Stagl (2002) que apontaram que razões sociais não eram as razões principais para a participação nos estágios iniciais desse mercado.

O risco da participação, isto é, a possibilidade de receber diferentes tipos de hortaliças ao longo do tempo do acordo, foi aceito por 18 consumidores. $\mathrm{O}$ risco foi aceito porque as famílias podiam consumir qualquer tipo de hortaliça e os respondentes consideraram que os produtores não poderiam prever o que aconteceria nas lavouras. Um consumidor não aceitou os riscos porque "isso não seria vantajoso para mim".

Os 12 consumidores (39\%) que não aceitaram participar do mercado alternativo apresentaram diversas razões. Quatro consumidores alegaram que os agricultores urbanos não produziriam todos tipos de hortaliças que eles gostariam de consumir. Nesse caso eles ainda necessitariam ir ao Mercado Central. Cooley \& Lass (1998) também encontraram que a restrição da oferta de produtos era um dos motivos pelos quais muitas famílias não participavam desse mercado. Quatro consumidores não aceitariam participar porque não conheciam nem os produtores, nem a horta urbana. Pode ser que o conhecimento da horta e dos agricultores mudasse a opinião desses consumidores. Dois consumidores preferiam ir ao Mercado Central, já que esse era considerado o único passeio que faziam; um consumidor achava que os produtos da horta eram mais caros e um outro achava o projeto um acordo difícil.

Em resumo, os resultados mostraram que alguns consumidores poderiam participar do mercado alternativo. Consumir vegetais frescos que chegavam da horta para a residência foram as principais vantagens apontadas.

Disposição dos agricultores urbanos de Santo Antônio do Descoberto de participar do mercado alternativo "AAC" - A área cultivada por cada produtor em 04/09 era menor que $200 \mathrm{~m}^{2}$. Como observado nos últimos três anos, a área de cultivo era reduzida na estação chuvosa (outubro a abril). A ocorrência de doenças era o principal fator que levava a essa redução. Por outro lado, a ausência desse problema na estação seca aumentava a área cultivada para $300 \mathrm{a}$ $500 \mathrm{~m}^{2} /$ agricultor.

Ainda que os agricultores tivessem problemas para o cultivo de suas áreas, 12 tipos de hortaliças, adaptadas às temperaturas de verão e de ciclo curto, eram cultivadas nos lotes. O cultivo de hortaliças de ciclo curto é importante para esses agricultores porque elas aumentam a disponibilidade de alimentos ao longo do ano e geram renda rapidamente, o que contribui para garantir a sobrevivência da família (Gockowski et al., 2003).

A renda obtida pelas famílias com a comercialização dos produtos da horta era bastante variável. Duas famílias obtinham um salário mínimo/mês; três obtinham 0,25 salário mínimo/mês. A horta era considerada uma atividade que 


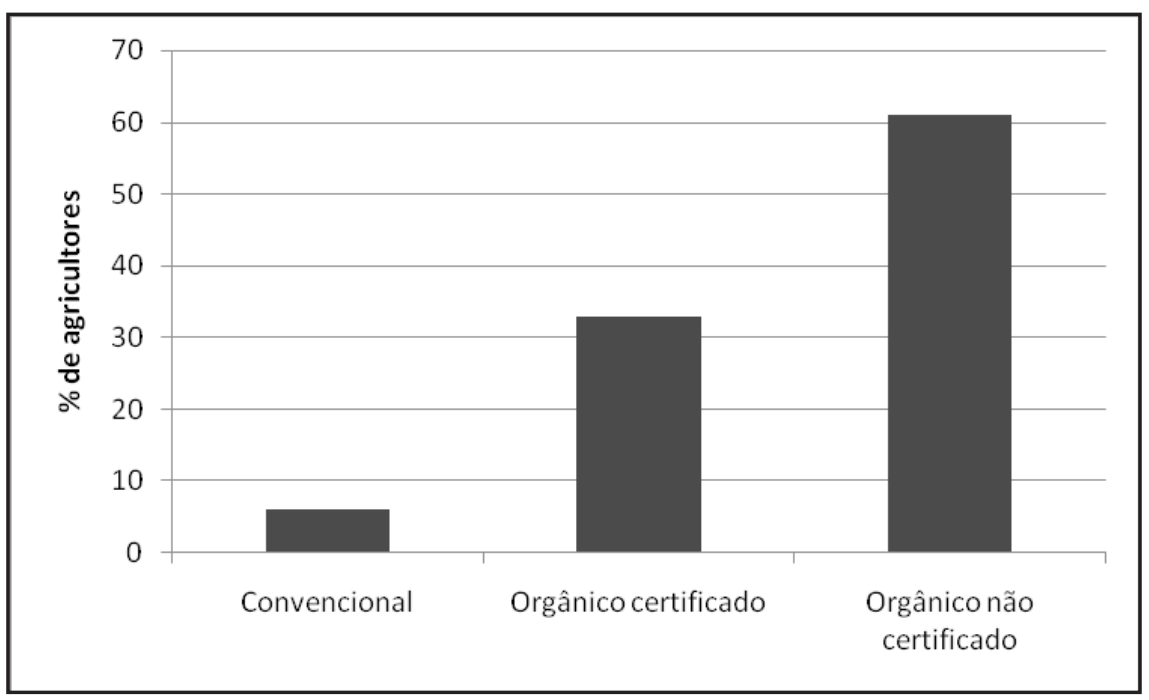

Figura 3. Sistema de produção usado no mercado alternativo $\mathrm{AAC}(\mathrm{n}=98)$ (production system used in different CSAs). College Park, Universidade de Maryland, 2008.

complementava a renda familiar, uma vez que todos os participantes tinham outros tipos de atividades remuneradas informais.

No que se refere ao uso de fertilizantes na horta, três agricultores usavam cama de frango ou esterco de gado, um usava restos vegetais e o outro usava fertilizantes químicos. A cama de frango havia sido doada pela Embrapa Hortaliças em 2008 e o esterco havia sido doado pelo governo local em ocasiões esporádicas em 2008 e 2009. Dois agricultores recolhiam esterco nas fazendas da região e gastavam de uma a duas horas diárias nesse precário trabalho, que exigia grandes deslocamentos. Esses agricultores eram os de menor renda familiar no projeto. Apenas dois agricultores tinham capital próprio para adquirir adubo. Um comprava esterco de um fazendeiro da região e outro adquiria pequenas quantidades ( $1 \mathrm{~kg}$ por vez) de adubo químico. Assim, vemos que muitos agricultores, embora trabalhassem longo tempo na horta, tinham pouco capital disponível e ainda dependiam da irregular contribuição do governo local, o que certamente afetava a continuidade da produção.

No que se refere à aquisição de sementes, o mesmo problema era observado. As sementes eram adquiridas de forma individual, em pequenos pacotes, o que aumentava o custo de produção. Em 2005-2006 tentou-se organizar um fundo comum para a aquisição de sementes, mas os seguintes problemas foram encontrados: a) os agricultores desejavam cultivar diferentes tipos de hortaliças; b) em algumas ocasiões alguns agricultores não tinham o capital necessário para o fundo. Tendo em vista os problemas encontrados, os agricultores decidiram que iriam adquirir individualmente as sementes, quando o subsídio governamental ao projeto acabasse.

Cinco produtores informaram que somente adquiriam as sementes "quando tinham dinheiro sobrando". Isso porque a maior parte da renda obtida com a venda de hortaliças era usada para atender as necessidades básicas da família. Isso significa que em algumas ocasiões, ainda que houvesse espaço para o cultivo de hortaliças, isso não ocorria.

Reuther \& Dewar (2005) sugerem que, para evitar o problema da aquisição de sementes, os produtores deveriam produzir esse insumo. Em algumas ocasiões os agricultores dessa horta urbana tentaram produzir sementes de quiabo e coentro. No entanto, eles concluíram que era necessário ocupar a terra por um longo período com culturas que não davam um retorno econômico adequado e as sementes produzidas não tinham boa qualidade. A produção de sementes de boa qualidade demanda trabalho, terra e infraestrutura, fatores esses limitados na horta (Nascimento, 2005). Por essa razão, esses agricultores urbanos chegaram à conclusão que era melhor adquirir as sementes no mercado local.

Em resumo, foi observado que os agricultores dessa horta urbana, após terem sido capacitados e contarem com subsídios governamentais para produção entre 2004 e 2007, contavam em 2009 com escasso apoio governamental, escassa organização social e limitado capital para manterem as suas lavouras, problemas semelhantes aos observados em outros locais (Monteiro \& Monteiro, 2006; Villas Bôas, 2006; Hampwaye et al., 2007).

Quando perguntados se aceitariam participar do mercado alternativo AAC, nenhum dos agricultores se mostrou interessado na idéia. A razão principal para a falta de interesse era a impossibilidade de garantir a produção. A garantia da produção era uma das maiores dificuldades dos produtores americanos, como visto anteriormente. Não podemos esquecer que os agricultores americanos são mais educados e têm acesso a informações. Esse não era o caso desses agricultores urbanos brasileiros. Eles tinham baixo nível educacional, limitado acesso a informações e assistência técnica.

Desse modo, a implantação de um projeto com assistência técnica, algum subsídio financeiro governamental e com envolvimento de técnicos que pudessem contribuir para a organização social da comunidade e a construção de uma rede cooperativa com a comunidade local, ou seja, com os consumidores, poderia contribuir para a sustentabilidade da horta urbana. Assim, a pergunta que se coloca é: se esses agricultores urbanos pobres tivessem o apoio governamental e da comunidade, poderia o mercado alternativo aqui apresentado, ser uma alternativa para atender a um dos principais objetivos do Ministério do Desenvolvimento Social e Combate a Fome quando financia esses projetos, ou seja, poderia esse projeto viabilizar a autonomia dos produtores urbanos?

\section{AGRADECIMENTOS}

Ao Dr. Félix Humberto França, do LABEX-USA e ao Dr. José Amauri Buso da Embrapa Sede, pelo apoio para 
a realização desse trabalho.

\section{REFERÊNCIAS}

BAIER A. 2005. Organic certification process. Arkansas: Appropriate Technology Transfer for Rural Areas (ATTRA). 8 p. Disponível em http://attra.ncat.org/attra-pub/PDF/organic certification.pdf_Acessado em 5 de janeiro de 2009.

CASTELO BRANCO M. 2007. Custos e benefícios do Projeto Horta Urbana de Santo Antônio do Descoberto. In: CASTELO BRANCO M; ALCÂNTARA FA; MELO PE (ed). O projeto horta urbana de Santo Antônio do Descoberto. Brasília-DF: Embrapa Hortaliças. p. 77-87.

CASTELO BRANCO M; NOGUEIRA JM; SANTOS RC. 2006. Perfil dos consumidores de hortaliças da cidade de Santo Antônio do Descoberto-GO. Horticultura Brasileira 24: 368-372.

COOLEY JP; LASS DA. 1998. Consumer benefits from Community Supported Agriculture Membership. A comparison of CSA share versus retail produce value. Review of Agricultural Economics 20: 227-237.

GOCKOWSKI J; MBAZO'O J; MBAH G; MOULENDE TF. 2003. African traditional leafy vegetables and the urban and peri-urban poor. Food Policy 28: 221-235.

HAMPWAYE G; NEL E; ROGERSON CM. 2007. Urban agriculture as local initiative in Lusaka, Zambia. Environmental and Planning C: Government and Policy 25: 553-572.

MINISTERIO DO DESENVOLVIMENTO SOCIAL E COMBATE A FOME. 2009. Seleção Pública de propostas para apoio a projetos de agricultura urbana. Edital MDS/SESAN $n^{\circ}$ 09/2009. Disponível em http://www.mds.gov.br/segurancaalimentar/ editais/editais-anteriores/2009/ agricultura-urbana/agriculturaurbana/?searchterm=AGRICULTURA $\% 20$ URBANA. Acessado em 28 de junho de 2010.

MONTEIRO JPR; MONTEIRO MSL. 2006. Hortas comunitárias de Teresina: agricultura urbana e perspectiva de desenvolvimento local. Revista Iberoamericana de Economia Ecológica 5: 47-60. Disponível em http:// ddd.uab.cat/pub/revibec/13902776v5p47.pdf . Acessado em 11 de novembro de 2009.

NASCIMENTO WM. 2005. Produção de sementes de hortaliças para a agricultura familiar. Brasília: Embrapa Hortaliças. (Circular Técnica 35). 16 p. Disponível em http://bbeletronica.cnph.embrapa.br/2005/ct/ ct_35.pdf Acessado em 3 de junho de 2009.

NATIONAL AGRICULTURAL STATISTICS SERVICE. 2009. 2007 Agricultural Census. United States Department of Agriculture, Washington, D.C. February. 4 p. Available at http://www.agcensus.usda.gov/ Acessado em 14 de janeiro de 2009.

OBERHOLTZER L. 2004. Community Supported Agriculture in the Mid-Atlantic Region: results of a shareholder survey and farmer interviews. Stevenville, MD: Research from the Small Farm Success Project. Disponível em http:// www.winrock.org/wallace/wallacecenter/ documents/wc-CSAReport.pdf_Acessado em 16 de dezembro de 2008.

O'HARA SU; STAGL S. 2002. Endogenous preferences and sustainable development. Journal of Socio-Economics 31: 511-527.

OLIVEIRA KES; SANTOS MA. 2007. Impactos da horta urbana de Santo Antônio do Descoberto na alimentação das famílias. In: CASTELO BRANCO M; ALCĂNTARA FA; MELO PE. Hortas Comunitárias; o Projeto Horta Urbana de Santo Antônio do Descoberto. Brasília; Embrapa Hortaliças. p.73-76.
PESSÔA CC. 2006. Agricultura urbana e pobreza: um estudo no município de Santa Maria-RS. Santa Maria: Universidade Federal de Santa Maria. 102p (Tese mestrado). Disponível em: http://cascavel.cpd.ufsm.br/tede/tde busca/ arquivo.php? codArquivo=1643. Acessado em 19 de novembro 2010.

PIROG R; RASMUSSEN R. 2008. Assessing fuel efficiency and $\mathrm{CO} 2$ emissions of two local food distribution options in Iowa. Iowa: Iowa State University/Leopold Center for Sustainable Agriculture. 11 p. Disponível em http://www. leopold.iastate.edu/pubs/staff/files/fuel0608. pdf Acessado em 20 de fevereiro de 2009.

REUTHER S; DEWAR N. 2005.Competition for the use of public open space in low-income urban areas: the economic potential or urban-gardening in Khayelitsha, Cape Town. Development Southern Africa 23: 97-122.

SEGUNDO JJMM. 2002. Urban agriculture project in the Conjunto Palmeira Slum, FortalezaCeará, Brazil. Urban Agriculture Magazine 7: 10-11. Disponível em: http://www.ruaf.org/ sites/default/files/Urban $\% 20$ Agriculture $\% 20$ Project $\% 20$ in $\% 20$ the $\% 20$ Conjunto $\% 20$ Palmeira\%20Slum.pdf. Acessado em 28 de junho de 2010.

SOHNGEN B; SEDJO R. 2006. Carbon sequestration in global forest under different carbon price regimes. The Energy Journal Special Issue 3: 109-126.

TEGTMEIER E; DUFFY M. 2005. Community Supported Agriculture in the Midwest United States: a regional characterization. Iowa: Leopold Center/Iowa State University. 23 p.

VILLAS-BÔAS MLS. 2006. How Community Gardens function: a case study of "Complexo Aeroporto", SP, Brazil. Ohio: Ohio University. $93 \mathrm{p}$ (Tese mestrado). Disponível em http://www.ohiolink.edu/etd/send-pdf.cgi/ VillasB244as\%20Maria\%20L250cia\%20 Soares.pdf?acc_num $=$ ohiou 1149463363 . Acessado em 14 de agosto de 2009. 